\title{
An Investigation of Preschool Children's Screen Exposure in Terms of Social and Emotional Developments
}

\author{
Selma Ozuslu Unal \\ Istanbul Gelisim University, Vocational School of Health Services, Istanbul/Turkey \\ E-mail: sozuslu@gelisim.edu.tr \\ Sibel Hakli \\ Istanbul Gelisim University, Vocational School of Health Services, Istanbul/Turkey \\ E-mail: shakli@gelisim.edu.tr \\ Kubranur Bayazit \\ Istanbul Gelisim University, Vocational School of Health Services, Istanbul/Turkey \\ E-mail: 170502071@ogr.gelisim.edu.tr
}

\begin{abstract}
Preschool is an invaluable step in an excellent exercise for the 0-6-year-old range below. In this period, children on the screen meet earlier than in the past year. It generally consists of this information about the approach. It is for this problem in children. In this thesis, the social and emotional effects of screen exposure in the preschool period were examined. It has been created with information from general to specific, consisting of collections of social, technological development and social programs in children. Parents have been looked at from the use of child games. Before the education of children's interaction with the screen, the basic points are mentioned and explained with child education.
\end{abstract}

Keywords: Preschool period, Technology, Screen, Social and emotional development

DOI: $10.7176 / \mathrm{JSTR} / 7-08-06$

\section{Okul Öncesi Dönem Çocuklarının Ekran Maruziyetinin Sosyal ve Duygusal Gelişimleri Açısından Íncelenmesi}

\begin{abstract}
Özet
Okul öncesi dönem 0-6 yaş aralığını kapsayan, kişinin yetişkinlik sürecine geçişinde çok değerli bir basamaktır. Bu dönem aralığındaki çocuklar, geçmiş yıllara göre ekranla daha erken tanışmaktadır. Özellikle teknolojinin hızla ilerlediği bu dönemlerde, çocukların ekrana bağımlı olma aşamasından önce bilinçli ya da bilinçsiz olarak maruziyet durumu oluşmaktadır. Çocuklardaki bu problem durumunun birçok sebebi vardır. $\mathrm{Bu}$ tez çalışmasında okul öncesi dönem çocuklarındaki ekran maruziyetinin sosyal ve duygusal açıdan etkilerine bakılmıştır. Çocuklarda sosyal, duygusal gelişim, sosyal beceriler ve bu becerileri etkileyen etmenlerden bahsedilerek genelden özele doğru yaklaşımla bilgiler derlenmiştir. Ebeveyn çocuk ilişkisinin çocuklarda ekran kullanımına olan etkilerine bakılmıştır. Çocukların ekranla olan etkileşiminin bağımlılık durumuna gelinmeden temel noktalarına değinilerek teknoloji, çocuk, ebeveyn üçgeniyle açıklanmaktadır.
\end{abstract}

Anahtar Kelimeler: Okul öncesi dönem, Teknoloji, Ekran, Sosyal ve duygusal gelişim 


\section{Giriş}

Günümüzde çocuklar, teknolojinin her alanına hakimiyet kurmuş şekilde yaşamlarını sürdürmektedir. Teknolojinin çocuklar üzerindeki etkileri düşünüldüğünde olumlu ve olumsuz açıdan sonuçlara ulaşılmaktadır (İnci ve Kandır, 2017). Çocuklar açısından hayatın ilk altı yılı temelde alınması gereken bilgi ve becerileri kazanarak, gelişimlerinin basamaklarını oluşturmalarından kaynaklı önemlidir (Yavuzer, 2020). Beyin gelişiminin çoğunluğu 0-4 yaş aralığında tamamlandığı durumuna bakıldığında; erken dönemde çocuğa oluşturulacak ortamlar uyarıcılar ve gelişimine hitap eden destek programlar çocuğun beyin gelişiminde önemli etkendir (Şahin, 2016). Sunulacak ortamın niteliği doğrudan çocuğun bedensel, ruhsal, zihinsel ve sosyal açıdan gelişimini de etkilemektedir (Çukur, 2011). Bu sebeple çocukların motor, bilişsel, sosyal ve duygusal ve öz bakım beceriler gibi gelişism alanlarını bilmek ve birbirleriyle etkileşim içerisinde olan bu alanları destekleyici şekilde ilerlemek, teknolojik araçların etkisini öngörmek, aile ve çocuk açısından değerlidir (Özdemir, 2019).

Çocuğun ilk dönemlerdeki sosyal uyum ve becerilerinin gelişmesi, sonraki yıllardaki sosyal uyum ve beceri oluşumu için temel oluşturmaktadır. Bu sebeple çocuğun okul öncesi dönemdeki sosyal uyum ve becerilerinin geliștirilmesi çok önemlidir. Kișinin huzurlu șekilde hayatını devam ettirmesi ve toplumun sağlıklı şekilde devamlılığına destek sağlayan sosyalleşme aşamasındaki birey, bazı sosyal becerileri kazanması ve geliştirilmesi beklenilmektedir. Okul öncesi dönemde bulunan çocuğun sosyal açıdan uyum yeteneklerinin desteklenmesiyle; diğerleriyle sağlıklı etkileşimler kurması, işbirliği içinde çalışması, diğer insanların haklarına karşı saygı duyması, kendisine hitap etmeyen istekleri reddetme ve ihtiyaç halinde diğer kişilerden destek isteyebilmesi gibi becerileri göstermesi beklenilmektedir. Çocuğun bu becerilerine destek için ebeveynlere ve diğer eğitimci kişilere sorumluluklar düşmektedir (Günindi, 2011). Ebeveynlerin, özellikle hızlı değişimlerin olduğu teknolojik çağda sorumluluklarının gerekliliği olaraktan yeni yeterlilikler kazanmaları gerekmektedir. Bunlardan biri, dijital dünyadaki tehlikelerin farkındalığı ve çocukları için önlem alma yeteneği, tıpkı çocuğunuzu gerçek hayatta bekleyen tehlikelerin farkında olma ve önlem alma becerisi gibidir (Yaman, 2018).

Teknolojik cihazların (televizyon, bilgisayar, tablet, cep telefonu) çocukların günlük hayatlarına girdiği zamandan bugüne kadar bilişsel, duygusal ve sosyal gelişimlerini etkilemeye devam etmektedir (Tüzün, 2002). Okul öncesi dönem çocukları, çevresel etkenlere duyarlı olduklarından ötürü bu dönemde güvenli internet kullanımına dikkat edilmelidir (Yaylacı, 2019).

\section{2. İnternet Bağımlılığı}

İnternet, birçok bilgisayar sistemlerinin birbirleriyle bağlantılı olduğu, dünya üzerinde yaygın şekilde bulunan ve sürekli büyümekte olan iletişim ağıdır. Aynı zamanda, bireylerin günden güne artmakta olan "üretilen bilgiyi saklama / paylaşma ve ona kolayca ulaşma" istekleri sonrası meydana gelen teknolojidir. Teknolojinin vasıtasıyla birçok alanda bulunan bilgilere kişiler kolay, hızlı ve güvenli bir şekilde erişim sağlamaktadır. İnternete, farklı açıdan bakıldığında başka tanımlarda getirilmektedir. İnternet, kişilerin herhangi bir konuda düşüncelerini kısıtlanmadan, özgürce söyleyebilecekleri platformdur (Özkan, 2010).

Hayatımızın bir parçası haline gelen internet, çocuklar için yepyeni bir dünyanın kapısını açarak hem çocuklara hem de ailelere yeni firsatlar ve deneyim firsatları oluşturmaktadır. İnternetin etkin kullanımıyla çocuklar, zaman ve yer sınırlaması olmaksızın her an bilgiye erişebilmekte ve yaptıklarını dünyaya iletebilmektedir. Ancak internetin sunduğu bu imkanların yanı sıra bazı riskler de içermektedir. Gerçek hayatta karşılaşılabilecek tehlikeler internet üzerinden de bulunabilmektedir. Yetişkinler internette olabilecek herhangi olumsuz durumla karşılaştıkları süreçte problemi kolaylıkla çözebilirken, çocukların bu konuda desteğe ihtiyaçları vardır.

İnternette çocukların ilgisini çekebilecek üç ortam bulunmaktadır. Bunlar; web siteleri, elektronik posta ve sohbet odalarıdır. $\mathrm{Bu}$ üç ortamın çocuklara avantajları olabileceği gibi kontrol edilmediği, bilinçsizce kullanım sonucunda uyarılmadığı durumlarda tehlike oluşturacak şekildedir (Özkan, 2010).

\section{Dijital Ebeveynlik Tutumu}

Dijital göçmen olarak adlandırılan ebeveynlerin, dijital yerli çocuklarını dijital ortamlarda karşılaşabileceği zararlardan koruyabilmek ve bu tür ortamları etkili olarak kullanabilmeleri amaçlı uyum sağlayabilmesi için olması gereken bir aşamadır. Çocukların yaş grubuna bakıldığında, ergenlik öncesi dönemde çocuğu olan ebeveynlerin bu dönemde dijital araçların kullanımına göre sorun oluşturabilecek problemlerin önüne geçmesine kolaylık sağlamaktadır (Manap, 2020). Çocukların sosyal, duygusal, psikolojik ve diğer gelişim alanlarını etkileyebilecek olan bu konuda ebeveynlerin çocukların dijital hayatlarında iyi birer kılavuz olabilmeleri ve teknolojinin bilinçli kullanım şekillerini uygun şekilde aktarabilmeleri amaçlı sahip olmaları gereken özellikler "dijital ebeveynlik" terimini ortaya çıkarmaktadır. Dijital ebeveynlik tanım aralığında "dijital" kelimesiyle anlatılmak istenilen; 
oyun, eğlence, araştırma amaçlı istenilen alana hitap edilerek, ilgi ve isteğe göre kullanımı değişebilen teknolojik araçlardır (Yay, 2019). Ebeveynler çocuklarının dijital teknolojilere erişimini istenilen düzeyde tutma, bu teknolojilerin bilinçli kullanımını sağlama ve bu süreçte de zarar görmelerini önleme gibi roller üstlenmişlerdir. Günümüzde ebeveynler çocuklarını gerçek hayata hazırlarken sosyal yaşam becerileri ve meslek edinme gibi becerilere bir de dijital ortam becerileri eklemekle yükümlüdür. Özellikle İnternetle hızlı şekilde değişen dijital yaşam, gerçek hayata göre yeni olması bakımından aile hayatına sonradan dahil olmuş, kendi değerlerini oluşturmaya başlamıştır. Ebeveynlerin, özellikle yaşanılan hızlı değişim sürecine alışarak ebeveyn sorumluluklarının gerekliliği olaraktan yeni yeterlilikler kazanmaları gerekmektedir. Bunlardan biri, dijital dünyadaki tehlikelerin farkındalığı ve çocukları için önlem alma yeteneği, tıpkı çocuğunuzu gerçek hayatta bekleyen tehlikelerin farkında olma ve önlem alma becerisi gibidir (Yaman, 2018).

\subsection{Anne-Babaların Dijital Ebeveynlik Rolleri}

Yay (2019) göre modern dönemdeki dijital çağın fırsatlarından ve kolaylıklarından en güzel şekilde yararlanmak ve çocuklarını olabilecek tüm problem durumlarından korumak isteyen ebeveynlerin üzerine düşen temel "dijital ebeveynlik" rol ve sorumluluklarını, Dijital Okuryazarlık, Farkındalık, Kontrol, Etik ve Yenilikçilik başlıklarına ayrılmaktadır.

\subsubsection{Okuryazarlık}

Pek çok teknolojik gelişmeyle beraber okuryazarlık kavramına "dijital okuryazarlık", "teknoloji okuryazarlığı" tarzında yeni terimler dahil olmuştur. Dijital okuryazarlık terimiyle anlatılmak istenilen, başlangiç seviyesinde teknolojiyi ve interneti kullanma becerisiyle bilgi-iletişim teknolojileriyle bağlantılı olan gizlilik politikaları hakkında açıklamalara hâkim olmaktır. Çocuk açısından internette rahatsızlık hissettiren durumla karşılaşıldığında bunu ilk olarak akranlarıyla paylaşma isteğinin oluşması, çocuğun ebeveynin internet ortamıyla olan ilişkisinde, bilgisinde duygu ve düşüncelerinin uygulanış halidir. Bununla beraber dijital araçlar hakkında yeterli bilgisi olmayan ebeveyn, çocuğunun neler yaptığına dair fikir sunmasında ve sağlıklı kullanım için yönlendirmesinde sorunlar yaşayabilmektedir (Yay, 2019).

\subsubsection{Farkındalık}

Dijital okuryazar olmanın yanı sıra, dijital ebeveyn olan bir kişi olumlu ve olumsuz içerikleri ayırt edebilir ve çeşitli risklerin farkında olabilmektedir. Böylelikle çocuklarının bilgisayarda veya internette nasıl vakit geçirdiklerini takip edebilecek birer birey durumunda olmaktadırlar. Bugüne bakıldığında gelişen toplumlarda internet, ailelerin birlikte geçirdikleri zaman diliminde değerli bir yere sahiptir. Dolayısıyla dijital ebeveynlik rollerinin farkındalığının rolü son derece önemlidir (Yay, 2019).

\subsubsection{Kontrol}

Farkındalık bilinci yüksek olan ve dijital ebeveyn olmakta istekli olan birey, çocuğunun dijital ortamlara dahil olduğunda davranış ve tutumlarını kontrol isteği oluşacaktır (Yay, 2019). Dijital ortamlarda karşılaşılan içeriklerin olumsuz taraflarına şahit olunduğunda, kendi belirledikleri tekniklerle çocuklarını koruma durumu göstermelidirler. Özellikle de belirli bir yaş grubuna hitap edildiğinde olabilecek bazı tehlikelerden korumanın en verimli yolu, çocukların dijital araçları kullanırken bazı kontrol süreçlerinden geçmektir (Manap, 2020).

Yay (2019) göre dijital ebeveynlerin kontrol durumunda edinmesi gereken özellikler şunlardır:

- Çocuğunu internet gibi geniş ve belirsiz bir boşlukta yalnız bırakmama durumu

- Zararlı olarak tanımladığı gönderi ve içeriklere ulaşılmasına engel olma, nedenlerini çocuğun anlayabileceği şekilde açıklama ve filtre programları tarzında yazılımlar kullanma.

- Problemli ve bilinçsizce kullanım durumu olmaması adına ne zaman ve ne kadar internet veya bilgisayar kullanabileceğine göre kısıtlamaların olduğu bir kitapçık hazırlama ve konulan kurallara uyma.

- Beraber sosyal medya kullanımı (Facebook, instagram gibi sosyal ortamlarda arkadaş ekleme, kaydolma, birlikte internette kontrollü ve bilinçli zaman geçirme)

\subsubsection{Etik}

Dijital dünyayla bağlantılı olabilecek ilgili literatüre bakıldığında etik kavramı iki şekilde ele alınabilmektedir. Birincisi; ebeveynlerin çocuklarının dijital teknolojileri kullanım ortamını kontrol etme görevini yerine getirirken, sınırlarına bakıldığında etik kuralların neler olabileceğiyle bağlantılıdır. 
Anlatılmak istenilen ebeveyn kontrolüne hangi koşullarda, ne ölçüde izin verilmelidir. Bu durumlarda çocuğun yaş grubuna göre kontrollerin değişebileceği gibi sorulara dikkat edilmelidir. İkincisi; ebeveynlerin ve çocukların dijital teknoloji kullanımlarında etik kurallara dikkat etmeleri gerektiğidir. Dijital teknolojilerin kişilere sunmuş olduğu sosyal medya programları, sohbet, oyun, alışveriş gibi programların hepsi kurumsal olup olmamasına bakılmadan birtakım meslek gruplarıly gerçekleşmektedir. Genelde çevrim içi oyunların bazılarında kişilerarası etkileşimler bulunmaktadır. Bu durum etik problemlerin dijital ortamlarda da incelenmesine dikkat edilmesini gerektiğini vurgulamaktadır (Manap, 2020). İnternette bireylerin hakları ve haysiyetine, özel hayatın mahremiyetine ve bilgi ahlakına uygun hareket etme etik rolüdür. Ayrıca elde edilen bilgilerin doğruluğunun ve güvenliğinin araştırılmasını, hak sahiplerinin istekleri doğrultusunda hareket edilmesini ve fikri mülkiyete saygı gösterilmesini gerektirmektedir (Yay, 2019)

\section{Teknoloji Ve Çocuk İlişkisi}

21. yüzyıldaki teknolojik gelişmeler insanın hayatında önemli bir konuma sahiptir. Teknolojide yaşanan gelişmeler, insanların daha rahat ve pratik yaşamalarına destek sağlarken; bunun yanında bilgiye ulaşarak yeni kanallar açarak bilgiye ulaşmayı kolaylaştırmıştır. Teknoloji, küçük yaşlardan başlayarak akıllı telefon ve tablet gibi dijital cihazlarla tanışarak çocukların sosyal hayatlarının vazgeçilmez parçası haline gelmiştir. Bu teknolojik gelişmelerin çocukların sağlığı üzerindeki etkilerini bilmek ve gözlemlemek daha sonrasında gereken önlemleri uygulamak kaçınılmazdır. Aileler, çocukların daha bilinçli yetişmesi amacıyla bilgisayar ve internet kullanımını eğitim açısından desteklemektedir. Ancak ailelerin çoğunun bilgisayar ve internet kullanımında yeterli bilgiye sahip olmadıkları görülmektedir. Teknolojik aletleri bilinçli şekilde kullanıma hazır olmayan çocuklar bazı karmaşık bilgileri değerlendirme konusunda sorun yaşamaktadır (Cömert ve Kayıran, 2010). Ancak günlük yaşamın vazgeçilmez unsuru durumuna gelen teknolojiyi kullanım şekli ve sunduğu olanaklardan yararlanmanın, teknolojinin zararlarının en aza indirgenmesine yararı olacağı düşünülmektedir (İnci ve Kandır, 2017).

\subsection{Okul Öncesi Dönemde Teknoloji Kullanımı}

Günümüzde çocuklar çok küçük yaşlarda teknolojik aletler ve ekranla tanışmaktadırlar. Doğum sürecinden altı yaşa kadar olan zaman kavramı erken çocukluk dönemi için kullanılmaktadır. Kademeli ve birbiriyle uyum içinde ilerleyen gelişimin temelleri yaşamın ilk yıllarında atılmaktadır. Okul öncesi dönem, bir insanın hayatı için en kritik dönemdir. Çünkü bu dönemde pek çok davranışın ve kişilik özelliğinin basamakları oluşmaktadır. Okul öncesi dönem, ilk üç yaş grubunun dil, oyun ve sosyal beceri gelişimi bakımından oldukça hassastır. Sosyal beceriler, oyun ve dil bir bütün olarak birbirleriyle karşılıklı etkileşim halindedir. Bu becerilerin gelişim aşamasında çocuğun ailesi, yaşıtları ve çevresiyle etkileşim süreci çok kıymetlidir (Özkılıç, 2019). Bu süreçte ebeveynlere büyük görevler düşmektedir. Çünkü çocukların bugüne kadar öğrenmiş olduğu bilgiler sadece çocukluk döneminde sabit kalmayarak, öğrendiklerini yetişkinlik dönemlerine kadar aktarabilmektedir. Özellikle 0-6 yaş kapsayan dönemde teknolojik aletlerin kullanımında zarar ve fayda oranlarına çok dikkat edilmelidir. Gerektiği durumlarda bir uzmandan destek alınarak oluşabilecek riskler engellenmelidir (Aral ve Keskin, 2018).

Teknolojik araçların yaşama dahil olmasıyla "oyun oynuyorum" cümlesi "Gerçek oyun, sanal oyun" şeklinde iki farklı anlamda düşünülmektedir. Günümüzde çocukların sokakta oynadıkları süre azalmış, hızlı kentleşmeyle çocuklar evlerde oynanabilecek oyunlara yönelmiştir. Evde çocuklara hitap edecek oyunlar mekândan kaynaklı bazı kısıtlamalara sebep olmaktadır. Tüm bu sebeplerden ötürü çocukların oyun algısı değişmiş ve artık çocuklar, sınırlamanın olmadığı durumlarda sanal oyuna gerçek oyundan daha çok ilgi duymaya başlamıştır. Çocuklarda oyun oynama süreleri 2 aylıktan 7 yaşına kadar artmaktadır. Okul dönemine gelindiğinde ise gerçek oyuna ayırdıkları zaman azalmaktadır (Duman ve Koçak, 2013).

\subsection{Bilgisayar ve İnternet Teknolojisinin Kötüye Kullanımı}

Çocuk ve ergenler teknolojiyi bilinçli şekilde kullanırlarsa doğru bilgiye kolay erişebilme, akademik açıdan başarılarını destekleme gibi avantaj durumlarına sahip olabilmektedir. Bununla beraber internet, telefon, bilgisayar, tablet gibi çocukların kolayca ulaşabildiği dijital cihazlar, kontrolsüz ve bilinçsizce kullanıldığında; günlük hayattaki görevler aksatıldığında "teknoloji kötüye kullanımı" durumu oluşmaktadır. Böylelikle çocuk açısından zarar görme durumu söz konusu olmaktadır. Bu zarar doğrultusunda çocuklar yaş gruplarına göre tamamlamaları gereken gelişim ödevlerini eksik yaparak, akranlarından geride kalmaktadırlar. Kötüye kullanım durumunda aşağıdaki verilen gelişim alanları olumsuz açıdan etkilenmektedir. Bu gelişim alanlarında, teknolojiyi sağlıksız kullanmanın kişiyi geriye 
sürüklemesi zararlı kabul edildiği gibi, normal koşullarda olması beklenen gelişmelere de zarar verdiği bilinmektedir (Yay, 2019).

- $\quad$ Fiziksel Gelişime Etkisi

Bireyin bilgisayar, tablet gibi teknolojik cihazlarla uzun süreli ve bilinçsiz kullanımından dolayı yaşadığı problemler: Beden duruşunda olabilecek bozukluklar, kas ve kemikteki ağrılar, göz bozuklukları gibi kişinin fiziksel gelişimini olumsuz açıdan etkileyecek zararlar örnek oluşturmaktadır. Fiziksel gelişimin üç temel maddesi bulunmaktadır. Uyku, beslenme ve hareket önemli ihtiyaçlardandır (Yay, 2019).

- Sosyal Gelişime Etkisi

Sağlıklı sosyal gelişim için insanlar üç grup insan, yetişkinler, akranlar ve çocuklar tarafindan çevrelenmelidir. Bu süreç düzenli bir ilişki içerisinde olmalıdır. Bu konuda şimdiki toplumda yaşanılan en büyük sorun, sadece akranlarla bir ilişki olması ve bireyin daha yaşlı ve genç insanlarla kaliteli bir paylaşım ve etkileşim içinde olmamasıdır. Ayrıca bu üç grup insanla ilişkilerde aidiyet ihtiyacını karşılayabilme becerisi, kendini ifade etme ve karşı tarafı anlama becerilerinin geliştirilmesi ve insanlarla düzenli ve derin bir ilişki kurma becerisi sosyal gelişimin vazgeçilmezidir. Bu kısımda insanlar yakın çevresiyle sağlıklı bir ilişki kurmakta zorlanırken, internet ortamında yeni tanıştığı kişilerle kolaylıkla iletişime girebilmektedir. Uzak ve yakın çevredeki etkileşim dengesinin zarar görmesi sosyal gelişmeyi engellemekte, kötü niyetli kişiler tarafından kullanılmasına neden olmaktadır. Sağlıklı bir sosyal gelişim ortamında çocuğun sağlıklı ve etkili ilişkiler kurması beklenilse de, bu ilişkilerin yaş ilerledikçe daha derin ve topluma fayda sağlanması beklenilmektedir. Teknoloji kullanımı çocukları daha çok geri götürüyorsa veya gelişimlerini etkiliyorsa, bu durum teknolojinin kötüye kullanıldığının göstergesidir (Yay, 2019).

\section{Kitle İletişim Araçları}

Günümüzde kullanılan iletişim araçları hızlıca yaygınlaşmaktadır. Okul öncesi dönem çocuklarında, kullanılan araçların olumlu ve olumsuz açıdan etkileri bulunmaktadır. Bilinçli kullanıldığı takdirde, çocukların zihinsel ve dil gelişim alanlarına faydası dokunmaktadır. İzlenilen programların etkisiyle çocukların saldırgan tutum sergilemesi olası durumdur. Çocukta gözlemlenebilecek olumlu ve olumsuz etkiler çocukların yaş gruplarıyla bağlantılı olarak kullandığı süreyle ilgilidir. Ayrıca izlenilen programın konusu da oldukça önemlidir. $\mathrm{Bu}$ süreçte düzeni sağlama sorumluluğu ebeveynlere düşmektedir. Aile üyelerinin bu süreçteki tutumları çocuğun gelişim sürecinde büyük bir etki oluşturmaktadır (Işık, 2019).

\subsection{Televizyonun Sosyal Beceri Üzerindeki Etkisi}

Okul öncesi dönem çocukları, çevreye karşı doğrudan hükümler veremediğinden iyi ile kötü arasında ayrım yapmakta zorlanmaktadır. Bu sebeple öğrenmeye oldukça açıktır. Çocuğun kişilik gelişimi bakımından değerli olan bu süreçte çevrenin etkileri, bir ömür boyu devam edeceği davranışları işlenmektedir. $\mathrm{Bu}$ sebepten ötürü ebeveynler çocuklarının dişarıdan gelen etkilerini denetlemeli ve çocuğa önemli davranışlar vermelidir (Bertan vd., 2009).

Çocukların çevreyi taklit ederek öğrenmelerinin yaygın olduğu bu dönemde, televizyon seyretmek çocuklara birtakım olumlu ve olumsuz alışkanlıklar katmaktadır. Bu şekilde kazandırılan alışkanlıklar, ilerleyen zamanlarda çocukların sosyal becerilerine yansımaktadır. Televizyon, tek yönlü sosyalleşme fırsatı sunan teknolojik araçtır. Okul öncesi dönemdeki çocuk kişilik açısından gelişmediğinden televizyonda sergilenen kişi ve durumları model alabilmekte, doğru- yanlış seçimini tam anlamda yapamamakta, bu durumda televizyonu tek kaynak olarak kabullenmektedir. Televizyonda sergilenen çizgi diziler, bazı filmlerde bulunan kahramanlar ve durumlara tepkiler izleyenlerin tepkisini anlamak niyetiyle abartılmakta ayrıca günlük yaşamdan bambaşka şekilde gösterilmektedir. Okul öncesi dönem sürecinde olan çocuğun abartılı şekilde yansitılan kahramanları kendine model olarak görmesi, ilerleyen süreçlerde kendi davranışlarında abartma etkisinin gözlemlenmesine ve sosyal etkileşimlerinin etkilenmesine neden olabilmektedir (Göçen, 2011).

\section{Sonuç ve Tartışma}

Günümüzde teknolojinin güzellikleriyle, merak uyandırması, ilgi çekici yönüyle tanışmayan yok denecek kadar azdır. Böyle bir dönemde çocuklarında geri planda kalmadan hızlıca sürece dahil olduğu yadsınamazdır. Böyle bir sürece hızlıca ve kolayca dahil olabilen çocuklar çocuklarımız, acaba nasıl oluyor da eskiden beri teknolojiyle bir bütünmüş gibi uyum sağlayabiliyorlar temelde sorulması gereken soru budur. Bu durumun aslında birçok sebebi vardır. Öncelikle ebeveynlerden yola çıkılarak sorgulanmaya başlanılmalıdır. Çocuğun temelde ilk eğitimi aile ortamında başlamaktadır. Aile çocuk için eğitim gördükleri kurum niteliğindedir. Bu eğitimde çocuklar yetişerek olgunlaşmaya daha sonra

48 I P a g e

www.iiste.org 
çevresiyle etkileşimleriyle durumlar, kişiler arasında bağlantı kurmaya başlamaktadır. Aile kurumunun çocuk için önemi vurgulanarak temelde bu kurum içerisinde yer alan anne, baba, kardeşler gibi kişilerin tutum ve davranışlarının çocuktaki geri dönüşleriyle gözlemlemek mümkündür. Ailesiyle aynı zamanda sosyalleşen, eğitim gören çocuklar okul öncesi dönemine geldiklerinde çevresinde gözlemleyeceği ve model alacağı daha fazla kişi tanıyarak sosyal ve duygusal gelişimleri desteklenmektedir. Özellikle bu yaşlarda çocukların kolaylıkla ulaşabileceği dijital aletler doğrudan olumlu ya da olumsuz anlamda etkilemektedir. Olumsuz etkileri azaltarak olumlu etkileri artırmak öncelik ebeveynlerin doğru model olmasıyla gerçekleşmektedir. Burada ebeveynler sadece sözlü olarak aşırı ekrana bakmak, ya da dijital araçlarla sık sık vakit geçirmenin zararından bahsetse çocuğun bu durumu algılamasında tek başına yeterli değildir. Çocukların bu süreci sağlıklı ve bilinçli geçirmeleri için dijital aletlerin sorun yaratacak açıdan problem yaratacak kullanımlarının farkında olunması gerekmektedir. Burada önce çocukların yaş gruplarına dikkat edilerek sınırlamalar konulmalıdır. Bu kısımda dikkat edilmesi gereken, ebeveynlerin sınırlarını çocuklara net olarak yansıtmak ve esneklik göstermemektir. Aynı zamanda çocukların ne amaçla dijital cihazlarla etkileşime girdiğini bilmek süreci yönetmekte yardımcı olacaktır. Şöyle bir durumla karşılaşıldığında: Çocuğunuz dijital aletlerle araştırma yapma, onları keşfetmek, yeteneklerini geliştirmek için kullanıyorsa bu kullanımında çocuk açısından olumsuz etkisi olabilecek durum yoktur (Yay, 2019). Kısıtlama noktasında esnek davranmak çocukla ebeveyn arasındaki etkili iletişime göre değişiklik gösterebilir. Bu kısımlarda doğru anne ve babalıktaki rollerin çocukla olan etkili iletişiminin önemine dikkat edilmelidir.

\section{Kaynakça}

Akbaş, İ. (2019). Okul Öncesi Dönemde Sosyal Beceriler. Göller Bölgesi Aylık Hakemli Ekonomi ve Kültür Dergisi, 7(77).

Aral, N., Keskin, A. (2018). Ebeveyn Bakış Açısıyla 0-6 Yaş Döneminde Teknolojik Alet Kullanımının İncelenmesi. The Turkısh Journal On Addıctıons. 5(2): 317-348.

Baykoç, N. (2018). Hastanede Çocuk ve Genç. Ankara: Gazi Kitabevi, 2(142).

Bertan, M., Haznederoğlu, D., Koln, P., Yurdakök, K., Güçiz, B. (2009). Ülkemizde Erken Çocukluk Gelişimine İlişsin Yapılan Çalışmaların Derlenmesi (2000- 2007). Çocuk Să̆lı̆̆l ve Hastalıkları Dergisi, 1-8.

Ceylan, Ş. (2009). Vineland Sosyal- Duygusal Erken Çocukluk Ölçeğinin geçerlik-güvenirlik çalışması ve okul öncesi eğitim kurumuna devam eden beş yaş çocuklarının sosyal-duygusal davranışlarına yaratıcı drama eğitiminin etkisinin incelenmesi (Doktora tezi). Gazi Üniversitesi Eğitim Bilimleri Enstitüsü, Ankara.

Cömert, I., Kayıran, S. (2010). Çocuk ve Ergenlerde İnternet Kullanımı. Çocuk Dergisi. 10(4): 66170.

Cüceloğlu, D. (2006). İnsan ve Davranışı. İstanbul: Remzi Kitabevi, 15:(355)

Çukur, D. (2011). Okul Öncesi Çocukluk döneminde sağlıklı gelişimi destekleyici dış mekân tasarımı. SDÜ Orman Fakültesi Dergisi. 12: 70-76.

Deveci, F. (2011). Ergenlerde Karar Verme Stilleri ile Alg1lanan Sosyal Destek Düzeyi Arasındaki İlişkinin İncelenmesi. [Yüksek lisans tezi]. Adana, Türkiye: Eğitim Bilimleri, Sosyal Bilimler Enstitüsü.

Durualp, E., Aral, N. (2011). Oyun Temelli Sosyal Beceri Eğitimi. Ankara: Vize Yayıncılık, 2: (89).

Duman, G., Koçak, N. (2013). Çocuk Oyun Alanlarının Biçimsel Özellikleri Açısından Değerlendirilmesi (Konya İli Örneği). Türk Ĕ̆itim Bilimleri Dergisi. 11(1): 64-81. 
Efe, K. (2005). Okul Öncesi Eğitim Çağında Çocuğu Olan Ailelerin Denetim Odağı Türü ve Çocuklarının Sosyal Davranışlarını Denetlemeleri Arasındaki İlişki. [Yüksek lisans tezi]. İstanbul, Türkiye: İlköğretim Anabilim Dalı, Eğitim Bilimleri Enstitüsü.

Göçen, G. (2011). Televizyonun Konuşma Eğitimine Etkileri. [Yüksek lisans tezi]. Sakarya, Türkiye: Türkçe Eğitimi Anabilim Dalı, Eğitim Bilimleri Enstitüsü.

Günindi, Y. (2011). Bağımsız Anaokullarına ve Anasınıflarına Devam Eden Çocukların Sosyal Becerilerinin Değerlendirilmesi. Ahi Evran Üniversitesi Eğitim Fakültesi Dergisi. 12: 133-144.

Gültekin, M., Çubukçu, G. (2006). İlköğretimde Öğrencilere Kazandırılması Gereken Sosyal Beceriler. Bilig. 37: 155-174.

Işık, M. (2007). Anasınıfına Devam Eden Beş-Altı Yaş Çocuklarına Sosyal Uyum Ve Beceri Ölçeğinin Uyarlanması ve Uygulanması. [Yüksek Lisans Tezi]. Ankara, Türkiye: Çocuk Gelişimi ve Eğitimi, Eğitim Bilimleri Enstitüsü.

Işık, T. (2019). Okul Öncesi Dönemi Öğrencilerinin Öğrenme Stilleri ile Sosyal Yetkinlik ve Sosyal Becerileri Arasındaki İlişkinin İncelenmesi. [Yüksek Lisans Tezi]. Konya, Türkiye: İlköğretim Anabilim Dalı, Eğitim Bilimleri Enstitüsü.

İnci, M., Kandır, A. (2017). Okul Öncesi Eğitimde Dijital Teknolojinin Kullanımıyla İlgili Bilimsel Çalışmaların Değerlendirilmesi. Hitit Üniversitesi Sosyal Bilimler Enstitüsü Dergisi, 10(2): 1705-1724.

Kaya, K., Tuna, M. (2008). İlköğretim Çağındaki Çocukların Sosyalleşmesinde Televizyonun Etkisi. Sosyal Bilimler Dergisi, 17: 159-182.

Manap, A. (2020). Anne Babalarda Dijital Ebeveynlik Farkındalığının İncelenmesi. [Doktora Tezi]. Malatya, Türkiye: Rehberlik ve Psikolojik Danışmanlık, Eğitim Bilimleri Enstitüsü.

Özkan, E. (2010). İlköğretim II. Kademe Öğrencilerinin Bilgisayar-İnternet Kullanım Durumlarının Değerlendirilmesi (Uşak İli Örneği). [Yüksek Lisans Tezi]. Afyonkarahisar, Türkiye: İlköğretim Anabilim Dalı, Sosyal Bilimler Enstitüsü.

Öztürk, A. (2008). Okul Öncesi Eğitimin İlköğretim 1. ve 3. Sınıf Öğrencilerinin Sosyal Becerilerine Etkisinin İncelenmesi. [Yüksek Lisans Tezi]. Konya, Türkiye: Çocuk Gelişimi ve Ev Yönetimi, Sosyal Bilimler Enstitüsü.

Özdemir, M. (2019). 0-6 Yaş Arası Çocukların Gelişim Düzeyleri ile Annelerinin Örselenme Yaşantıları ve Aile Yaşam Kaliteleri Arasındaki İlişkinin İncelenmesi. [Yüksek Lisans Tezi]. Ankara, Türkiye: Çocuk Gelişimi ve Eğitimi Programı, Sağlık Bilimleri Enstitüsü.

Özkılıç, N. (2019). Üç Yaş Çocuklarda Teknolojik Alet Kullanımının Sosyal Beceri, Oyun Becerisi ve Dil Gelişimi Üzerindeki Etkilerinin İncelenmesi. [Doktora tezi]. İstanbul, Türkiye: Psikoloji, Sosyal Bilimler Enstitüsü.

Samanc1, O., Uçan, Z. (2017). Çocuklarda Sosyal Beceri Eğitimi. Atatürk Üniversitesi Sosyal Bilimler Enstitüsü Dergisi. 21(1): 281-288.

Şahin, S. (2016). 0-6 yaş arası çocukların temel gelişimsel özellikleri: Fiziksel ve sosyal-duygusal gelişim. Diken İ, editör. Erken çocukluk eğitimi. Ankara: Pegem Akademi, 138.

Tüzün, Ü. (2002). Gelişen İletişim Araçlarının Çocuk ve Gençlerin. Düşünen Adam. 15(I ):46-50.

Uçar, N. (2010). Okul Öncesi Öğretmenlerinin Sosyal Becerilerini Etkileyen Faktörler. [Yüksek Lisans Tezi]. Konya, Türkiye: İlköğretim Anabilim Dalı, Eğitim Bilimleri Enstitüsü. 
Uzamaz, F. (2000). Sosyal Beceri Eğitiminin Ergenlerin Kişilerarası İlişki Düzeylerine Etkisi. [Yüksek lisans tezi]. Adana, Türkiye: Eğitim Bilimleri, Sosyal Bilimler Enstitüsü.

Ulusoy, A., Aytar, A., Akyol, A., Subaşı, G., Ünver, G., Erdamar, G. (2015). Gelişim ve Öğrenme Psikolojisi. 8. bask1. Ankara: Anı Yayınc1lık, 110-121.

Yay, M. (2019). Dijital Ebeveynlik. 2.baskı. İstanbul: Yeşilay Yayınları, 16-43.

Yaman, F. (2018). Türkiye'deki Ebeveynlerin Dijital Ebeveynlik Öz Yeterliklerinin İncelenmesi. [Doktora Tezi]. Eskişehir, Türkiye: Bilgisayar ve Öğretim Teknolojileri Eğitimi, Eğitim Bilimleri Enstitüsü.

Yaylacı, B. (2019). Okul Öncesi Çocuklarda Ebeveyn Çocuk İlişkisinin İnternet Kullanımı Üzerine Etkisi. [Yüksek Lisans Tezi]. Zonguldak, Türkiye: Çocuk Sağlığı ve Hastalıkları Hemşireliği, Sağlık Bilimleri Enstitüsü.

Yavuzer, H. (2020). Çocuğunuzun ilk 6 yll.38. baskı. İstanbul: Remzi Yayınları, 9. 